\title{
An Explanation of the Levels of Compliance in Filing Company Annual Returns Based on the Theory of Planned Behavior: A Case for Zambia
}

\author{
Chimuka Mweetwa1, Jackson Phiri² \\ ${ }^{1}$ Graduate School of Business, University of Zambia, Lusaka, Zambia \\ ${ }^{2}$ Department of Computer Sciences, School of Natural Sciences, University of Zambia, Lusaka, Zambia \\ Email: mweetwachimz@gmail.com, jackson.phiri@cs.unza.zm
}

How to cite this paper: Mweetwa, C. and Phiri, J. (2019) An Explanation of the Levels of Compliance in Filing Company Annual Returns Based on the Theory of Planned Behavior: A Case for Zambia. Open Journal of Business and Management, 7, 1358-1379. https://doi.org/10.4236/ojbm.2019.73094

Received: April 12, 2019

Accepted: July 23, 2019

Published: July 26, 2019

Copyright $\odot 2019$ by author(s) and Scientific Research Publishing Inc. This work is licensed under the Creative Commons Attribution International License (CC BY 4.0).

http://creativecommons.org/licenses/by/4.0/

\section{(c) (i) Open Access}

\begin{abstract}
Company registers are increasingly becoming a crucial source of business information for many stakeholders. While most company registers have concentrated on simplifying business registrations, reducing the number of procedures, time and cost for small entities to be formed, compliance remains a big challenge for many company registers. Compliance is not just influenced by economic variables of enforcement and penalties but influenced by demographic, socio-economic and institutional factors. The aim of this study was to identify and explain the factors influencing compliance behaviour in filing company annual returns based on the Theory of Planned Behaviour. The study used a mixed research approach. A sample of 165 registered companies was randomly selected from the population of 68,049 active companies on the PACRA register. 9 PACRA officers were selected using judgment sampling and in-depth interviews were used. Primary data were collected through structured questionnaires. The secondary data were also collected by reviewing related published materials. Statistical tests of independence (chi-square tests) formed the basis of analysis. The results showed that annual return filings are influenced both by demographic and external factors. The demographic factors like employment status, age and education were found to positively influence compliance. Further, compliance was highest (68\%) among those with tertiary education compared with (47\%) those with no form of schooling. The study also revealed that those in formal employment were more compliant (64\%) than those without employment (47\%). Gender was found to be an insignificant factor and it has no influence on compliance. On external factors, cultural norms, government policies and compliance fees were identified in the study and were found to have an influence on compliance (save for compliance fees). Finally, the findings of the study may
\end{abstract}


guide government institutions to save on enforcement costs (i.e. before they implement costly sensitization campaigns and educational clinics, they need to understand variables that affect compliance behaviour). The study findings can help policy makers and PACRA meet their strategic goals of raising compliance levels.

\section{Keywords}

Compliance, Annual Returns, Company Register, Theory of Planned Behaviour, Demographic Factors, External Factors

\section{Introduction}

Business Registers ${ }^{1}$ hold a great deal of information, but the extent of the information depends on different legislations. Therefore, the higher the compliance levels, the more valuable ${ }^{2}$ the company registers are to local and international investors. High compliance also translates into more revenue generated for the government through compliance fees companies pay [1]. In other Jurisdictions like Singapore, United Kingdom, New Zealand and South Africa, company registers generate a lot of revenue $\mathrm{e}^{3}$ and are often used as a tool in promoting growth for the development of its nation [2]. The importance of company registers in different economies are several and to affirm their importance [3] it is noted that most governments are revamping their processes for company registrations in order to improve their competiveness. Undertaking formal registrations ensures that businesses benefit from increased legal rights, financial privileges, access to government services and limited liability. According to the Doing Business Report 2016, company registries across the world have invested heavily in ICT and Online platforms. Registers have evolved from manual to electronic or hybrid ${ }^{4}$. By 2012 according to the Doing Business Report, 2015 (54) economies had introduced new technology in their company registration processes in the last seven years while Sub Saharan Africa was the region with the highest number of reforms (83) followed by East Asia and the Pacific (45). Further the ranking in the ease of doing business globally is, Mauritius $\left(25^{\text {th }}\right)$, Rwanda $\left(41^{\text {st }}\right)$, Morocco $\left(69^{\text {th }}\right)$, Kenya $\left(80^{\text {th }}\right)$, Botswana $\left(81^{\text {st }}\right)$, South Africa $\left(82^{\text {nd }}\right)$ and Zambia $\left(85^{\text {th }}\right)($ a world Bank Group Doing Business, 2018). Because of the aforementioned and ease of company registrations, countries have recorded growth in company registrations but compliance levels in most Jurisdictions remain a big challenge. It could then be argued therefore, that there is a positive correlation between ease of doing business with increase in company registration (Doing business report, ${ }^{1}$ Also called company registers.

${ }^{2}$ Value in company registers may be defined as a register that has quality company information, easily accessible and more reliability \& this creates more demand hence more revenue.

${ }^{3}$ The quantification of a "lot" of revenue Refer, to CIPC, ACRA \& UK Company Annual Reports, 2016-2017.

${ }^{4} \mathrm{Hybrid}$ register is one which is both manual and electronic. 
2018) but there seems to be no correlation between ease of doing business with compliance levels or richer economies to high compliance levels in filing annual returns. PACRA in the last 5 years increased the budget on awareness but compliance levels have remained at $40 \%$. So many awareness activities have been undertaken but compliance is still at 40\% [4]. In 2012 penalty fees for filing annual returns were abolished [5]. Fees were reduced, Annual returns processes were simplified and the Register went Online in 2016 to enable electronic filing of annual returns. In order to curb this insurgence, the strategic plan 2016-2020 has now put a demand on PACRA to increase compliance from $40 \%$ to $70 \%$ but as of 2018 , company compliance in filling annual returns stood at $15 \%$ and overall registers compliance stood at $40 \%$. Low compliance levels result in foregone revenue by the government. Low compliance in filing annual returns is a common problem for most registers across jurisdictions and those company registers which seem to have attained both high registrations and compliance level seem to have arrived at this either accidentally through trial and error, or at the expense of huge enforcement costs, which if a cost to benefit analysis is done would be negative. Huge enforcement budgets are not even feasible for most developing countries especially in recent times of impacts of global recessions and usually enforcement teams are blamed for failed optimal results year in year out [6]. This again was at the heart of this research in trying to understand what variables affect compliance and how could companies attain compliance with ease. The use of some Data Analytics by adopting, the Theory of Planned Behavior in trying to understand compliance behavior and explain variables that are significant influencers to compliance in filing annual returns at PACRA formed the basis of this study. The objectives of the study are therefore to analyse the impact of demographic factors on compliance, to understand how compliance behavior is influenced by external factors and further device a working model that can be used to increase the level of compliance. The results of this study may be significant from both theoretical and practical standpoints. From a theoretical standpoint, the study may help in developing a comprehensive theory of compliance. From a practical standpoint the findings may be of help to PACRA, other government institutions and policy makers who will gain a better understanding of the factors that determine compliance for policy interventions. Enforcements are a costly undertaking and usually not cost effective, reduction in penalties may also not increase voluntary compliance [6]. Even increasing the fees may not sort out compliance issues. If compliance levels do not improve, the government losses out in terms of Revenue and PACRA's or any government Institutions which is an Agent of the government used to mobilise funds through providing a Public service, their ability to sustain themselves financially is compromised and so is their overall contribution to the Treasury.

This study is justified for a varied range of reasons. Firstly, global performance of corporate registries is assessed by the levels of compliance and number of business registrations in each jurisdiction. Compliance levels depict value of com- 
pany registers. Value for corporate registries is measured by the data quality, accessibility and reliability ${ }^{5}$. If compliance is high, it means value is high and hence more demand for registry information by stakeholders (local and foreign) and hence more government revenue, and contribution to the economy.

Currently compliance levels have remained at $40 \%$ for the last 5 years and PACRA has instituted measures as outlined in the earlier sections, and therefore a study of behavioral approach to compliance could help understand why compliance levels are low. The Patent and Company Registration Agency (PACRA) has over the years embarked on massive awareness and sensitization programs aimed at increasing compliance. Some of these new strategies include; creation of separate compliance and enforcement unit (2012), introduction of electronic filing systems, opening up offices in all provincial centers of Zambia and forming increased strategic alliances like the local authorities (councils) in remotest of areas to aid in filing of registrations. In addition, some legal reforms were introduced to further enhance compliance. For example, the Ministry of Justice abolished late filing fees, and in 2012 PACRA embarked on an amnesty campaign to pardon all defaulting companies that filed late annual returns.

However, despite these measures being put in place, the problem of noncompliance has continued to persist. According to the PACRA strategic plan (2016-2020) compliance levels currently remain at $40 \%$. For example, as at January 2019 , a total of 168,512 business are recorded in the companies' register of that, only 67,928 were submitting returns. This low level of compliance also translates into forgone revenue by government (filing fees). Therefore, this paper assesses factors that influence compliance behavior and what shapes their attitude to comply with the legislations.

The study focused on compliance levels in the last 5 years at PACRA. The survey information was obtained from five provinces within Zambia. These include; Lusaka, Copperbelt, Southern, Easter and Northern Provinces Respectively. The study is premised on realist ontology and inductive logic. However, the study was faced with some challenges with regards to time, resources and limited literature on the topic. The paper is organized as follows; Section 2 is the Literature Review, Section 3 is the Research Methodology, Section 4 outlines the Study results and discussions and, Lastly, Section 5 focuses on the conclusions and Recommendations of the study.

\section{Literature Review}

This section begins by defining key concepts of the literature review, definition of what an annual return is and compliance. The study then discusses the theoretical review and looks at related studies that provided a basis for analysis in this research.

\section{Definition of Concepts}

Annual Return-is a document that companies have to file at the registrar of

${ }^{5}$ Refer to the International Business Registers Report 2015. 
Companies each year at the end of the financial year. It contains details of the company's directors, shareholders and registered office address. An annual return is a statutory return in terms of the companies Act and is a summary of the most relevant information pertaining to a company or corporation. The prescribed filing fees for annual returns are legislated according to each different jurisdiction. Since the filing of annual returns is mandatory, different jurisdictions are governed by different corporate laws, in some failure of filing an annual return means the company can be struck out of the corporate register or penalties will accrue or the company secretary will be liable for the offence since this falls under the administrative duties of the secretary.

Compliance-the act or process of complying with the companies Act. Compliance means the action taken by companies to file the post incorporation procedures. In this case the action the companies take to file company annual returns. The word compliance in filing annual returns and filing of annual returns are used interchangeably. Compliance is a post registration requirement. Once a company is registered, it is supposed to file its annual returns each year on a selected date called a financial year end (FYE). A FYE is simply a company's anniversary date. It is therefore important to file annual returns because the higher the compliance levels in filing annual returns for a business register, the higher the value of the information held by the registers. Since value is difficult to define and measure, business registers use ascertain variables that could be interpreted as indicators of value and these are; the availability, quality, reliability, and accessibility of information which if these are higher, creates demand for information in the business registers

Registrar of companies-a registrar of companies is a public authority which is responsible for managing the companies register and deals with the administration of the Companies Act.

Company register-a register of companies in a given jurisdiction they operate under.

\section{Leveraging Technology to Support Business Registration Reform}

According to the doing business report (2016), Company registrars are deploying information and communications technology (ICT) applications to reduce the time and effort required for new businesses to register, improve regulatory oversight by government, and facilitate access to company information. Empirical evidence has shown that significant reductions in the time and costs required to register a business can have material effect on new registrations [4]. Therefore, leveraging on technology to improve client services and information sharing capabilities should be the top agenda of all business registration authorities. Now registries have digital signatures, e-payment, e-company searches, e-filing, e-registrations and e-requisitions. However irrespective of this, at the CRF conference (2016) in Hong Kong some registers have recorded success like the New Zealand, Singaporean registries, Mauritius and Rwanda. But Compliance in filling company annual returns remains a challenge especially for developing countries like Zambia. Compliance often is understood from an en- 
forcement or prosecution perspective according to the law but enforcement and prosecution comes at such a huge cost and they will usually achieve sub optimal results.

Figure 1 illustrates how A Company Registry acts as an information exchange hub for the private sector and government. Information contained in company registers is demanded for different uses among these players;

* Governments: Regulatory over sight;

* Financial Institutions: Risk analysis, if company is registered or not and directors or shareholders;

* Pension Schemes: Need Information on employers (helps administration of social security and pension payments);

* Law enforcement agencies: Information useful in carrying out investigations/compliance checks.

\subsection{Theoretical Review}

Over time a number of theories have formulated and have proved useful to model and understand compliance-related behaviour and the reasons behind that behaviour. These include; Economic Deterrent Models (EDM), Social-Psychology Models (SPM), The Theory of Reasoned Action (TRA), Social-Economic Theory of Regulatory Compliance and the Theory of Planned Behaviour (TPB). The underpinning theory for this study is the theory of planned behaviour. The underpinning theory for this study is the theory of planned behaviour, a theory that takes into consideration the role of social-psychological constructs regarding issues of decision making. The theory of reasoned action and its extension, the theory of planned behaviour [7] represent the models that are mostly used by social psychologists to try and understand human behaviour [8]. Figure 2 illustrates the theory of planned behaviour.

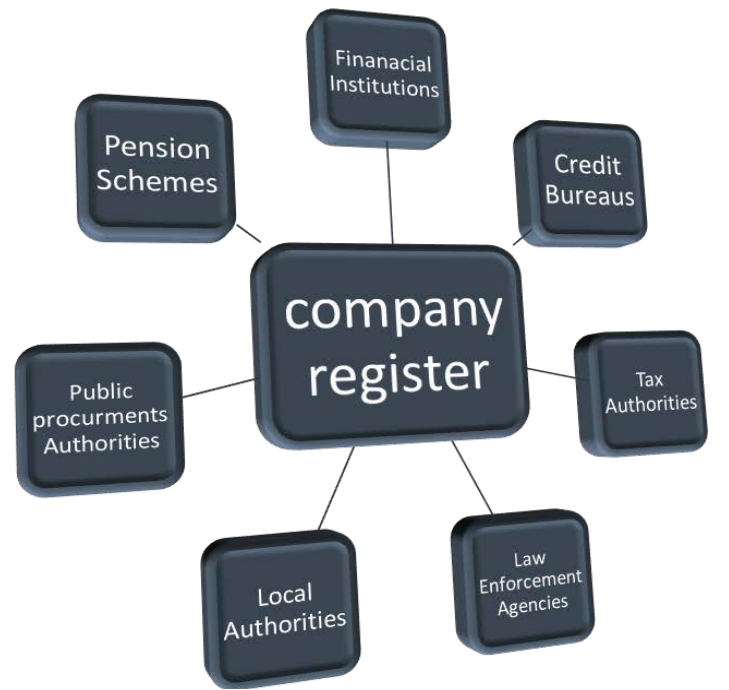

Figure 1. Users of Information contained in the companies' register. Source: researcher's own construction. 


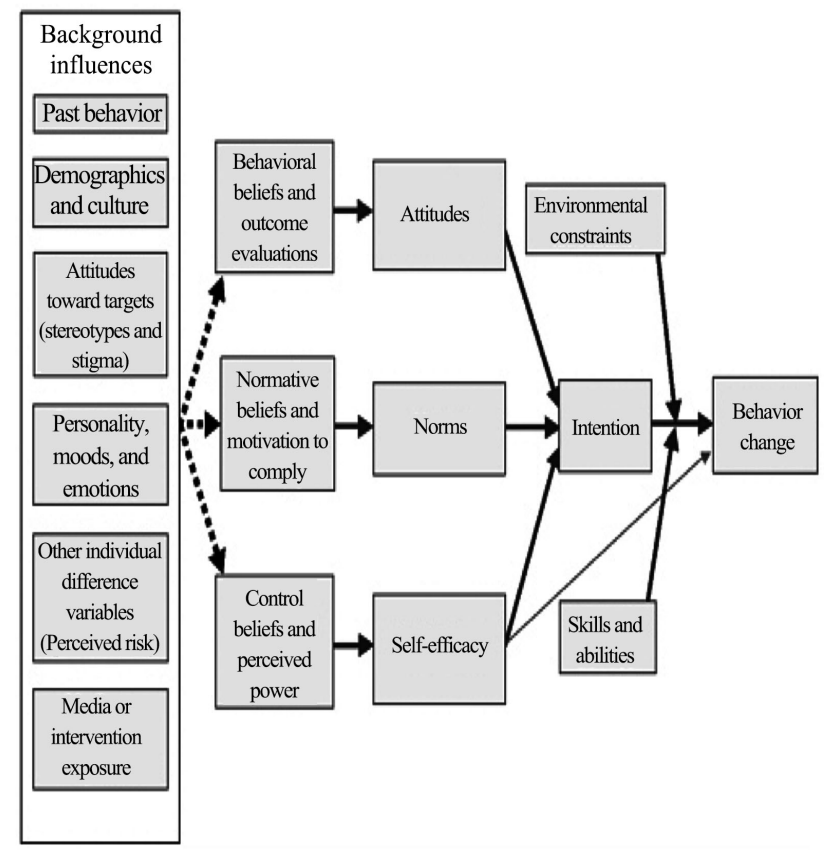

Figure 2. Model of theory of planned behavior. Source: Azjen (1991).

According to the model above, Ajzen's six constructs are crucial in circumstances/projects/programs when changing behavior of people. In their respective aggregates, behavioral beliefs produce a favorable or unfavorable attitude toward the behavior, normative beliefs result in perceived social pressure or subjective norm, and control beliefs give rise to perceived behavioral control [9]. In combination, attitude towards the behavior, subjective norm, and perception of behavioral control lead to the formation of a behavioral intention [10].

\subsection{Empirical Review}

A number of studies have made use of the Theory of Planned Behavior in predicting and shaping compliance behavior. In a recent study on the application of the Theory of Planned Behavior to Predict Young Drivers' Speeding Behavior, the results showed that young drivers' speeding behavior appeared to be affected by perceived behavioral control, past behavior, personal norms, intention to speed, affective and evaluative attitude towards compliance with speed limit, and social support. It also found that the impact of personal norms is greater in the intention to speed [11]. In another study, the application of the theory of planned behaviour was used in modelling tax compliance behavior in New Zealand. The results of this study suggested that noneconomic variables, such as beliefs and attitudes, are good predictors of tax compliance behaviour. Consistent with the majority of studies, the most influential factor in predicting and explaining tax compliance behaviour (through the mediating effects of behavioural intention) is attitude towards the behaviour. Other factors such as personal, social and societal norms were also significant predictors of tax compliance behaviour [12]. The theory of planned behaviour Prediction was also 
used in a study of self-monitoring compliance among sufferers of a chronic illness. The Theory of Planned Behaviour (TPB) made it possible to predict those clients who complied with medical guidelines, prescription drug intake, and self-monitoring behaviors (peak flow or blood sugar levels). Significant amounts of variance explained by the TPB model indicated its usefulness as a predictor of self-monitoring behaviour intentions in the sample [13]. In a study applying the theory of planned behaviour and structural equation modelling to Tax compliance behaviour. These findings also provided justification for the use of the TPB framework.

Related studies

\begin{tabular}{|c|c|c|c|c|}
\hline Title & Year & Authors & Findings & Gaps \\
\hline 1) A Study on Tax & \multirow[t]{7}{*}{1972} & Allingham and & The research revealed that the use of & The main gap relates to the assumption that \\
\hline Compliance Using & & \multirow[t]{6}{*}{ Sandmo's } & penalties and other deterrent measures & individuals make tax paying decisions in a social \\
\hline the Economical & & & such as enforcement were not the only & vacuum and overlooks the human elements or \\
\hline Deterrent Model & & & determinants of tax compliance, that & traits addressed in the theory of planned behaviour \\
\hline & & & enforcements come at such a huge cost & such as values, norms, morals, beliefs and attitudes \\
\hline & & & and high penalties don't always result in & towards tax compliance behaviour, involved in the \\
\hline & & & high compliance. & decision. \\
\hline
\end{tabular}

\section{2) Applying the Theory of Planned Behaviour and Structural Equation Modelling to Tax Compliance Behaviour: A New Zealand Study}

2012 Martha smart (1)

\section{3) Legacy: The} Reasoned Action Approach

4) Application of the Theory of Planned Behaviour to Predict Young Drivers' Speeding Behavior
2012 Azjen \& Fishbein's Concluded that the attitudes and social The Annals of the norms influence intentions, which then American Academy influence behavior. of Political and Social Science, 640(1), 11-27

MontiraKetphat,

2013 Kunnawee Kanitpong \& amp; Piyong Jiwattanakulpaisarn norms, intention to speed, affective and evaluative attitude towards compliance with speed limit, and social support. behavior appears to be affected by perceived
The research was conducted on Tax compliance and not Company compliance.

The findings revealed the importance of norms in tax compliance behaviour (personal, social and societal) and that non-economic variables also have an important role in tax compliance behaviour. The findings also provide justification for the use of the TPB framework for tax compliance research.

The research could have also looked at demographics such as age, gender and levels of experience and how these affect tax compliance behaviour in a person.

Perceived control which is the extension of TPB could also have been looked at i.e. how tax payers evaluate if tax they are paying improves their livelihood. If they see the good results tax becomes a moral obligation.

The research was conducted on Tax compliance and not Company compliance.

The RAP ended at social norms and attitudes as influencing factors to intentions of behavior but this is where the TBZ model is extended by Including controlled behavior as a factor to contribute to behavior intentions. The research was on Animal behavior and not Company compliance.

Results show that young drivers' speeding The speed fines in trying to control young drivers speeding behaviour could not explain young drivers speeding behaviour or neither did the fines control the behaviour. The attitude and subjective norms were not enough to explain the speeding behaviour. The theory of planned behaviour was applied to try and understand the behaviour of young drivers speeding and to control it.

The study was on young drivers speeding behaviour and not on Company registers compliance. 


\section{Continued}

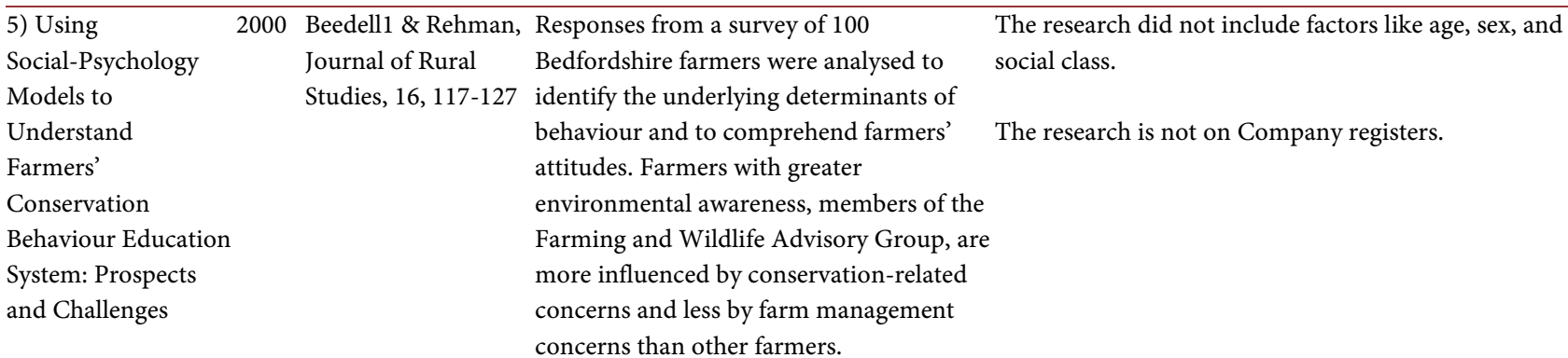

\section{Methodology}

\section{1) Research Design}

The study used a mixed research design (qualitative and quantitative approach). Descriptive statistics (Tables, graphs, figures and percentages) will be used to present the qualitative aspects of the survey data. While chi-square Independence tests formed the basis of the quantitative aspects of the data so as ascertain the relationships among our interest variables.

2) Study Population, Sample Size and Sampling Technique

Population consisted of all registered businesses under PACRA register (68, 049 companies). A combination of Cluster and random Sampling was used in the study (company register arranged according to provinces, then random samples selected from each cluster (province). Simple random sampling technique was used to select the registered businesses because it provides each element in the population with an equal chance of being selected. A sample of 160 registered businesses was selected.

3) Data Collection Procedures and Data Analysis

This study collected data through the use of both primary and secondary sources. Primary sources included administering questionnaires. The secondary sources of data were interviews with PACRA stuff and data collected from PACRA Annual reports. SPSS and MS Excel aided the analysis of both the qualitative and quantitative aspects of the data.

4) Response Rate

A total number of (160) one hundred and sixty questionnaires were organized and distributed to companies, of which (146) one hundred and forty-six questionnaires were filled completely and returned back. This has made the response rate around $91 \%$. After the data were collected, checked for errors and completeness. This study employed Chi-square tests of Independence for data analysis.

5) Reliability Analysis

In order for assessments to be sound, they must be free of bias and distortion. Reliability and validity are two concepts that are important for defining and measuring bias and distortion. Reliability refers to the extent to which assessments are consistent. Validity refers to the accuracy of an assessment-whether 
or not it measures what it is supposed to measure. Cronbach's Alpha is a statistical measure used to when you want to assess the internal consistency of a questionnaire (or survey) that is made up of multiple Likert-type scales and items. The closer, the Cronbach's alpha coefficient is to one, the more reliable the data is. The table displays reliability statistics from SPSS. Cronbach's alpha coefficient is 0.673 . This denotes a fairy high internal consistency. In this case, $\alpha=0.81$, which shows the data collection tool (questionnaire) was reliable. See Table 1.

\section{Results and Discussions}

Tables 2-4 give the percentages and frequencies of four variables; age, gender, education, and other economic occupation. The gender composition of the sample was 98 males (representing 67\% of the sample respondents) 48 females (33\% of the sample respondents). Survey results indicated that $17 \%$ of the respondents had primary level education while $21 \%$ had secondary education. Majority of survey respondents attended tertiary education (college/university) represented by $49 \%$ of the Sample and lastly, 19 respondents (13\%) had no form of schooling. On other economic occupation (i.e. alternative source of income), a total of 61 survey respondents were employed in the public and private sectors. This represented a total of $61 \%$ of the sample. A total of 85 (58\%) were self-employed. Figures 3 and Figure 4 depict the age groups and gender of the sample respectively.

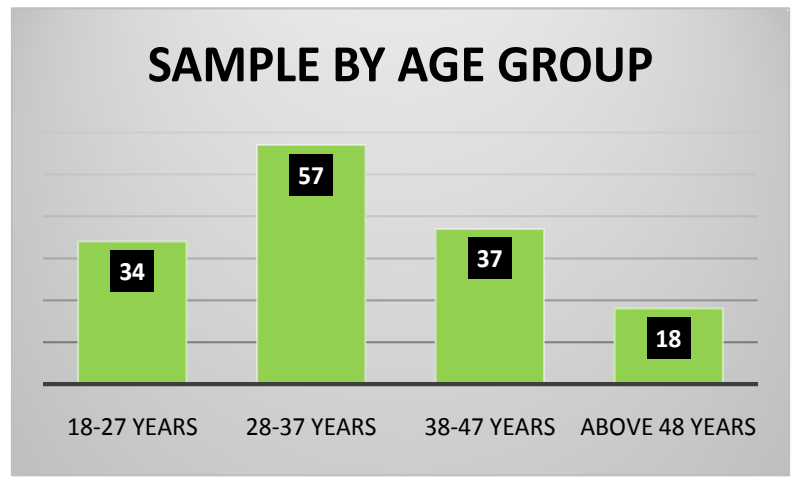

Figure 3. Age distribution if the sample.

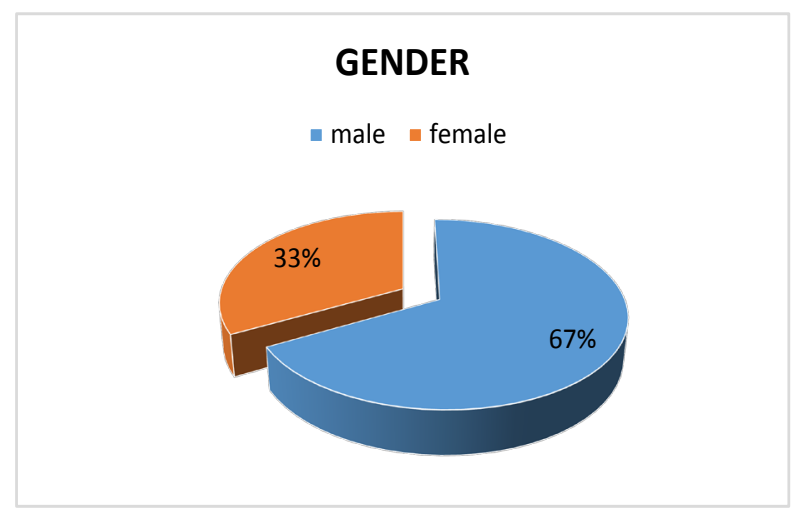

Figure 4. Sample distribution by gender. 
Table 1. Reliability statistics.

\begin{tabular}{ccc}
\hline Cronbach's Alpha & $\begin{array}{c}\text { Cronbach's Alpha Based on } \\
\text { Standardized Items }\end{array}$ & Number of Items \\
\hline 0.0673 & 0.679 & 4 \\
\hline
\end{tabular}

Table 2. Age distribution of sample.

\begin{tabular}{ccc}
\hline Age group & Frequency & Percent \\
\hline $18-27$ years & 34 & 23.3 \\
$28-37$ years & 57 & 39 \\
$38-47$ years & 37 & 25.3 \\
above 48 years & 18 & 12.3 \\
\hline
\end{tabular}

Table 3. Sample gender representation.

\begin{tabular}{cccc}
\hline Variable & & Frequency & Percent \\
\hline gender & male & 98 & 67 \\
& female & 48 & 33 \\
\hline
\end{tabular}

Table 4. Socio-economic demographics of respondents.

\begin{tabular}{cccc}
\hline \multirow{2}{*}{ Variable } & \multicolumn{2}{c}{ Demographic Characteristics of Respondents } & \\
\cline { 2 - 4 } & Table column subhead & Frequency & Percent \\
\hline \multirow{2}{*}{$\begin{array}{c}\text { Highest level of } \\
\text { education }\end{array}$} & Primary & 25 & 17 \\
& Secondary & 31 & 21 \\
Other economic & Tertiary & 71 & 49 \\
occuaption & None & 19 & 13 \\
\hline
\end{tabular}

\subsection{Chi-Square Tests of Independence}

\subsubsection{Education vs Compliance}

Table 5 is the cross tabulation of the relationship between compliance and education background. According to the Chi-square test statistics above, the observed p-value (0.003) is less than the significance level of 0.05 , we conclude that there is sufficient evidence to suggest, age has an influence on compliance. this is depicted in Figure 5.

\subsubsection{Gender vs Compliance}

Table 6 and Figure 6 depicts the relationship between compliance and gender. As seen, Females seem relatively more compliant. According to the Chi-square test statistics above, the observed p-value (0.716) is greater than the significance level of 0.05 , hence the test is insignificant and we conclude there is insufficient evidence to suggest, gender has no influence on compliance. 


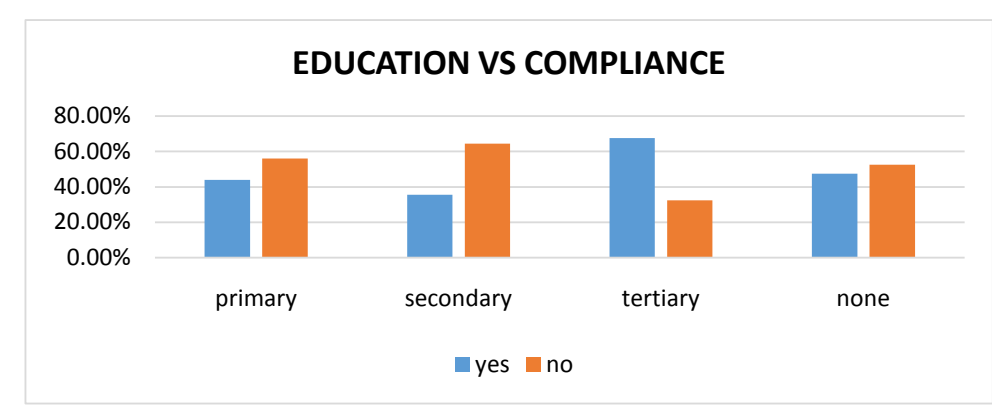

Figure 5. Education vs Compliance. * "Yes" indicates those that filled a return in the last 4 years and those that didn't by "No".

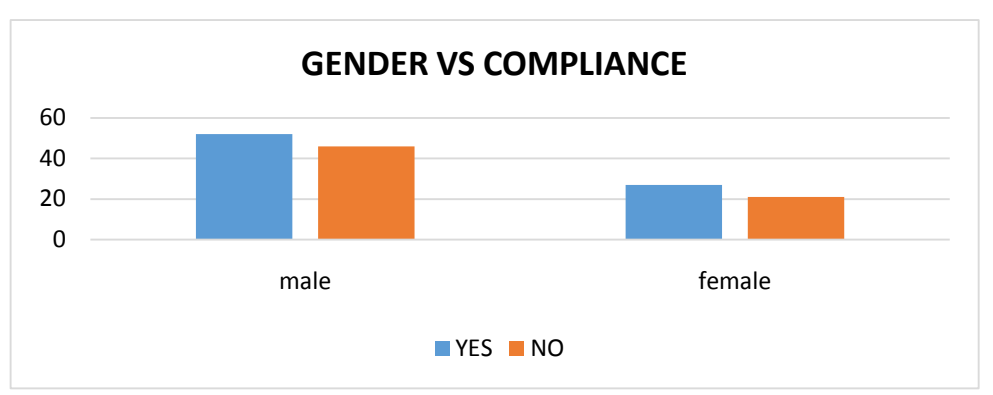

Figure 6. Education vs Compliance. * "Yes" indicates those that filled a return in the last 4 years and those that didn't by "No".

Table 5. Employment vs Compliance.

\begin{tabular}{cccc}
\hline Have you filled a return in the last 4 years & & Yes (\%) & No (\%) \\
\hline Education & primary & 44 & 56 \\
& secondary & 35.5 & 64.5 \\
& tertiary & 67.6 & 32.40 \\
& none & 47.4 & 52.6 \\
Total & & 54.10 & 45.9 \\
\hline
\end{tabular}

*Pearson Chi-Square test statistic 13.770 (p-value $=0.003)$.

Table 6. Gender vs Compliance.

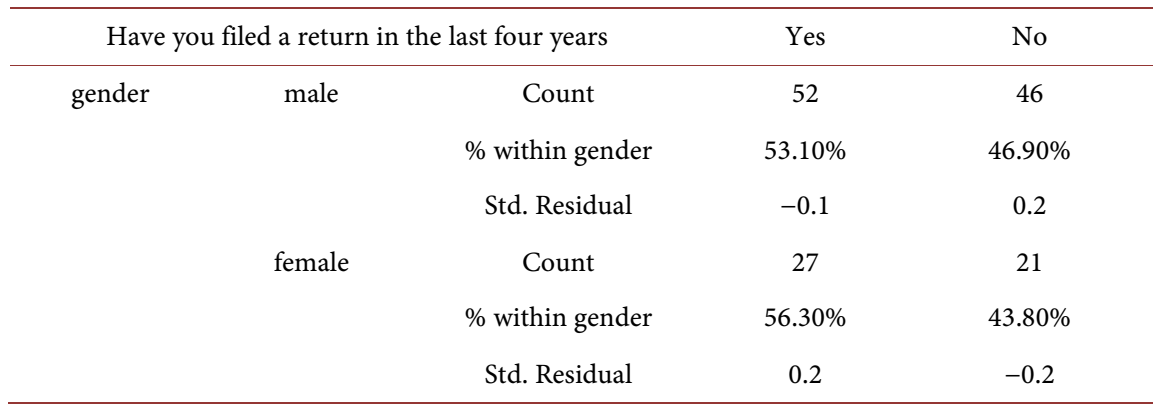

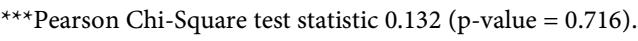

\subsubsection{Employment vs Compliance}

Table 7 depicts the relation between the relationship between employment status and compliance. As the results indicate that within those that are employed, 
the compliant respondents were in the majority $(64 \%$ compared with the non-compliant 36\%). According to the Chi-square test statistics above, the observed p-value (0.044) is less than the significance level of 0.05 , hence the test is significant and we conclude there is evidence to suggest, employment status has an influence on compliance

\subsubsection{Age vs Compliance}

Table 8 is the cross tabulation of the relationship between compliance and Age. The Chi-square test statistics above, the observed p-value (0.003) is less than the significance level of 0.05 , hence the test is significant we conclude there is evidence to suggest, age has an influence on compliance. This is depicted in Figure 7.

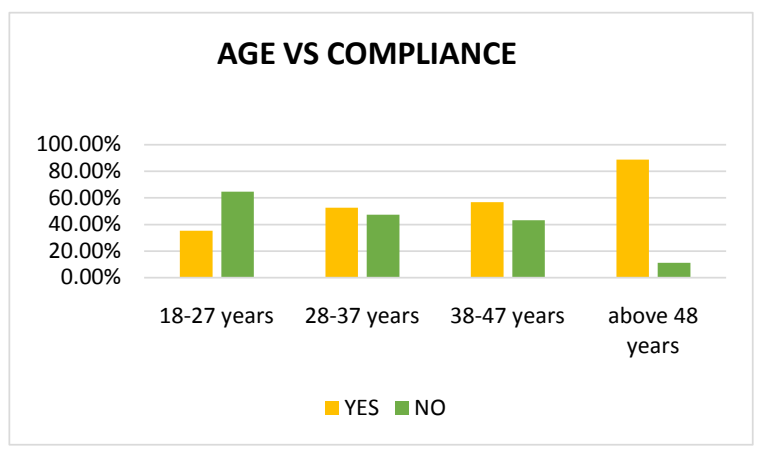

Figure 7. Age vs Compliance. * "Yes" indicates those that filled a return in the last 4 years and those that didn't by "No".

Table 7. Employment vs Compliance.

\begin{tabular}{cccc}
\hline Have you filed are turn in the last four years? & & Yes & No \\
\hline employed & Count & 39 & 22 \\
& & $63.90 \%$ & $36.10 \%$ \\
not employed & Count & 40 & 45 \\
& & $47.10 \%$ & $52.90 \%$ \\
& Count & 79 & 67 \\
& & $54.10 \%$ & $45.90 \%$
\end{tabular}

${ }^{\star}$ Pearson Chi-Square test statistic $0.132(\mathrm{p}$-value $=0.716)$.

Table 8. Age vs Compliance.

\begin{tabular}{ccc}
\hline Age group & Yes $(\%)$ & No (\%) \\
\hline $18-27$ years & 35.30 & 64.70 \\
$28-37$ years & 52.60 & 47.40 \\
$38-47$ years & 56.80 & 43.20 \\
above 48 years & 88.90 & 11.10 \\
\hline
\end{tabular}

${ }^{\star}$ Pearson Chi-Square test statistic $13.770(\mathrm{p}$-value $=0.003)$. 


\subsubsection{Social vs Compliance}

Table 9 is a cross tabulation of social norms and compliance (return filing). As shown above, it is not easy to come to a conclusion by merely looking at the frequencies above. Hence a chi square test of independence was used. According to the Chi-square test above, the observed p-value (0.013) is less than the significance level of 0.05 , hence the test is significant and we conclude there is evidence to suggest, social norms (family/friends) have influence on compliance.

\subsubsection{Government Agencies/Policies vs Compliance}

Table 10 and Figure 8 show the relationship between compliance and Government agencies/Policies. As seen, the majority of compliant respondents indicated that were highly influenced by government agencies/policies when filing returns. According to the Chi-square test results above, the observed p-value (0.001) is less than the significance level of 0.05 , hence the test is significant and we conclude there is evidence to suggest, Government agencies/NGOs has influence on compliance.

\subsubsection{Cost of Compliance (Filing Fees) vs Compliance}

Table 11 is the relationship between compliance and cost of compliance. The responses were mixed and the general picture as regards compliance is not very clear as seen above. So the surest way was to conduct an independent Chi-square test so as ascertain whether or not compliance fees have an influence on compliance. According to the Chi-square test above, the observed p-value (0.067) is greater than the significance level of 0.05 , hence the test is insignificant and we fail to reject the null hypothesis and conclude there is no evidence to suggest, filing fees have no influence on compliance. This is depicted in Figure 9.

Table 9. Social vs Compliance.

\begin{tabular}{llll}
\hline & \multicolumn{2}{l}{ Have you filed a return in the last four years } \\
\cline { 3 - 4 } & not highly influenced & 34 & No \\
\hline $\begin{array}{l}\text { To what extent are you } \\
\text { influenced by your }\end{array}$ & not influenced & 8 & 18 \\
$\begin{array}{l}\text { friends and family to } \\
\text { file returns? }\end{array}$ & neutral & 16 & 13 \\
& influenced & 10 & 9 \\
highly influenced & 11 & 1 \\
\hline
\end{tabular}

${ }^{*}$ Pearson Chi-Square test statistic $12.709(\mathrm{p}$-value $=0.013)$.

Table 10. Government agencies/Policies vs Compliance.

\begin{tabular}{ccc}
\hline $\begin{array}{c}\text { To what extent are you influenced by } \\
\text { government policies to file annual returns? }\end{array}$ & Frequency & $\%$ \\
\hline Not Strongly influenced & 29 & $19.9 \%$ \\
Not influenced & 19 & $13 \%$ \\
\hline
\end{tabular}


Continued

\begin{tabular}{ccc}
\hline Neutral & 20 & $13.7 \%$ \\
Influenced & 31 & $21.2 \%$ \\
Strongly influenced & 47 & $32.2 \%$ \\
\hline
\end{tabular}

${ }^{* * *}$ Pearson Chi-Square test statistic 8.785 ( $\mathrm{p}$-value $=0.001$ ).

Table 11. Cost of compliance vs Compliance.

\begin{tabular}{ccc}
\hline Filing fees of annual returns are affordable & Frequency & Percentage \\
\hline Strongly Disagree & 7 & $4.8 \%$ \\
Disagree & 67 & $45.9 \%$ \\
Neutral & 29 & $19.9 \%$ \\
Agree & 39 & $26.7 \%$ \\
Strongly Agree & 4 & 2.7 \\
\hline
\end{tabular}

${ }^{*}$ Pearson Chi-Square test statistic 8.785 (p-value $\left.=0.067\right)$.

\section{Government agencies/policies vs Compliance}

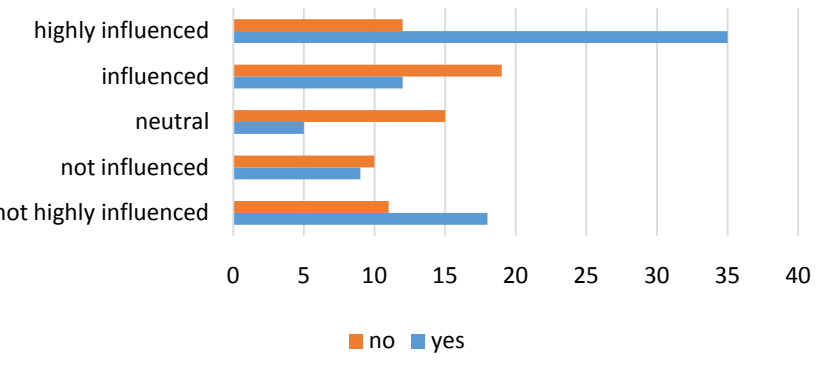

Figure 8. Government policy vs Compliance. " "Yes" indicates those that filled a return in the last 4 years and those that didn't by "No".

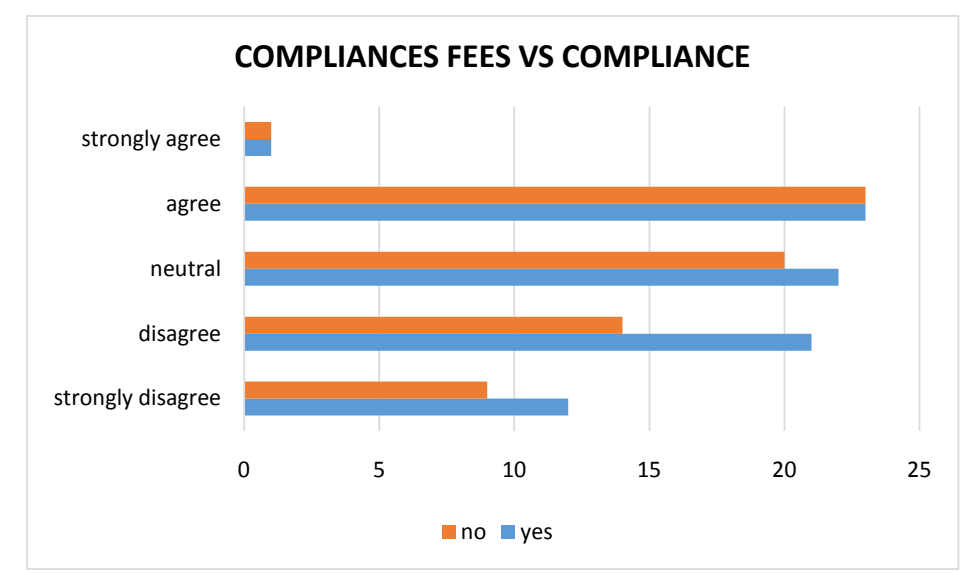

Figure 9. Government policy vs Compliance.

According to the results in the previous section, it was established that education has an influence on compliance. The observed results indicated that, the 
higher one's level of education is, the higher the compliance save for those with secondary education. Highly educated people understand the law and filing rules, while low educated people with little understanding are likely to make mistakes when filing their annual returns. Higher education is also associated with better access to information. On the other hand, Low literacy in general limits the understanding of one's duties, and opportunities may breed distrust and consequently non-compliance. As regards age, levels of compliance were noticeably higher with the older sections of the sample. An intuitive explanation could be that, the socialization of older generations differs from younger generations: social values, attitudes towards the state and towards compliance may change from one age cohort to another. In addition, with age the need for public goods such as social security and health care increases. Older citizens might, thus, treasure the benefits complying with statutory laws than younger population, hence tend to be more compliant.

On gender, survey results indicated a higher percentage of compliance among females as compared to males. The intuitive explanation could be women may perceive sanctions for noncompliance as more severe and threatening than men. Thus, female business owners tend to be more compliant than males. However, statistical tests on gender were found to be insignificant in this study and as such, the study concluded that gender has no influence on compliance. Regarding Employment status, levels of compliance were noticeably for those that were in formal employment than those unemployed. The plausible explanation for this may be those in formal employment are in most cases educated and in this study we have already established that education does in fact influence compliance. In addition, access to information is relatively easier for those in formal employment (e.g. can easily access the internet at the office, easily interact with technocrats or professionals in various field during such things as workshops, company meetings etc.) and as such this may increase one's awareness of statutory obligations. Besides demographic factors affecting filing compliance attitudes of citizens, social life of business owners has its own impact on compliance attitude. There is an existing social bond between the society and this bond influences the members of the society in complying with the legal regulations. For example, Perceptions of equity or fairness may influence how company owners comply. People with the same income or wealth brackets should pay the same amount filing fees and those with higher incomes to pay a relatively higher amount. In Zambia, compliance fees are fixed across the board, and that may present some implications on compliance. Thus government policies also shape the level of compliance. According to the results in the previous section, the observed results indicated social norms (family/friends) have influence on compliance. Therefore, a referent group (peer influence) has an impact on compliance attitude. Decisions either to comply or not sometimes are influenced by family members or friends. Therefore, the influence of referent groups is seemingly important in making a decision, particularly involving monetary aspects 
and the obedience to laws. In addition, societal norms or positive (or negative) perceptions of others compliance behaviour, also positively influenced intentions to comply with government agencies/policies and compliance, the study established that Government Agencies/Policies have an influence on compliance. With regard to changes in government policies as factors that affect compliance attitude, studies have disclosed that the government decisions and changes to policies in accordance with the economic and political situation have a significant impact on compliance [6]. For example, a positive move made by political situation has a significant impact on compliance attitude. Lastly, the researcher wanted to understand to what extent compliance fees affect filing compliance. For example, a positive move made by a political situation, for example introduction of entrepreneurship grants through empowerment schemes, coming up with community initiatives to offer training or providing small startup capital have a significant impact on compliance attitude because business owners develop a positive behavioral control. They feel they are being cared for by the government or that the money they spend on Compliance is after all being put to good use. An analogy to this is compliance in paying tax increasing if business owners perceive that the tax they pay is being put to good use e.g. repairing roads, improved health facilities or increase in the provision of the quality of other public goods. Lastly, the researcher wanted to understand to what extent compliance fees affect filing compliance. The statistical tests were insignificant, hence the conclusion that filing fees don't influence the level of compliance. This may suggest that whether the Register increases fees for lodgments, reduces the fees in the hope of increasing compliance, abolishment of penalties or adding penalties or undertaking an amnesty ${ }^{6}$, this may temporarily increase compliance in the immediate short run, but will not increase voluntary compliance in the long run. This formed the heart of the research and the findings reviewed the importance of understanding variables that impact compliance behavior. Understanding Compliance behavior is crucial for achieving voluntary ${ }^{7}$ compliance.

PACRA should segment its sensitization and awareness campaigns according to the specific needs of various stakeholders needs. Of Interest is the youth cohort whose results were found to be significant to Compliance. In order to improve Compliance among youths, PACRA should go a step further than ending at offering registration services but partner with other strategic alliances (both government and non-government) which empower youths. PACRA could This approach is consistent with the findings in the Literature review of what CIPC (Republic Of South Africa's Register) does in its effort to increase business registrations and compliance among youths. This has worked well in South Africa amidst high unemployment levels ${ }^{8}$. By using this approach Youths develop a positive perceived controlled approach that the register cares for their needs, ${ }^{6} \mathrm{An}$ amnesty is scrapping off or abolishing outstanding fees in penalties for a registered company in years of non compliance in the hope of encouraging \& increasing compliance.

${ }^{7}$ Voluntary Compliance is important for the registries revenue generation. ${ }^{8}$ CIPC 2017 Company Annual Report. 
concerned about their welfare and hence they will voluntarily comply. Unlike the Adult cohorts who are responsible and ethical and would want to comply voluntarily with minimal educational messages the youth cohorts as reviewed by the study needs attention to enable them comply.

The research also revealed that most registers had undertaken Legal reforms (Doing business report, 2016). Registers were leveraging on technology, were Online but this is not a solution to an end. The fully Online application processes may include Online payment systems and fees, digital signatures, Online searches, Online name clearances and filing of other company lodgments. However irrespective of technological enhancements, failed cases in other registers were experienced and registers had to go back to the manual system. In order for Technology to yield both efficiency registrations and increase in compliance needed is to understand compliance behavior. Further, if the cost of digitizing old company records especially for bigger registries is higher, it is recommended to undertake a cost to benefit analysis and settle for a hybrid ${ }^{9}$ register.

\section{Conclusions and Recommendations}

With the understanding of the above, the results of this study illustrate that the TPB, which is based on attitudes and behaviour, offers a useful framework for understanding compliance behaviour. This theory offers an accurate framework to predict compliance behaviour and combines it with the economic deterrent models espoused in this study. Government and non-government institutions could yield more effective results, thereby become more viable, and sustainable and contribute to the treasury. The problem of compliance especially in developing countries is because of lack of empirical study in and therefore more studies in understanding compliance behavior using the TPB should be encouraged to explore factors that are likely to strongly influence intentions to comply (or not comply). Refer to Figure 10.

The findings suggest that in order for PACRA, to improve compliance behaviour, the authority should monitor closely those business owners who may not perceive fairness and trustworthiness in government agencies/policies. The results also suggest that to improve compliance, PACRA should target company owners who are younger as they have the lowest levels of compliance. On education, PACRA must enhance its efforts in educating the public on compliance matters (identifying repeating defaulting ${ }^{10}$ directors in compliance, and offering them training as option for reduced penalties through formal and informal channels) community drama plays, appointing focal point people who can be educating others in local languages. Furthermore, business owners need more information about their legal obligations and their role in promoting the growth of the economy of the country and the well-being of its citizens. In addition,

${ }^{9} \mathrm{~A}$ registry which is both manual \& Online.

${ }^{10}$ This is consistent with what ACRA (Singaporean Company Registers does). They identify defaulting companies in filling company annual returns and provide training to repeat offenders (Directors) as a way to remedy noncompliance behavior. 


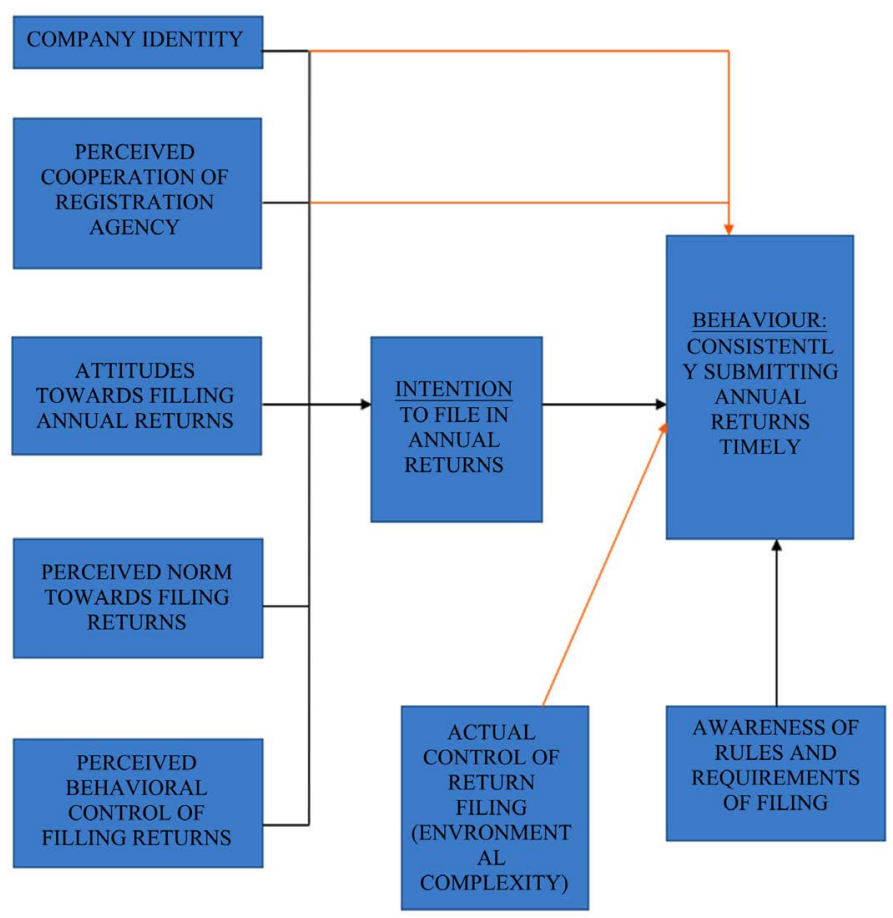

Figure 10. Model of theory of planned behavior applied to compliance. Source: researcher's own construction.

PACRA should consider providing the public with various payment options e.g. banks, mobile money facilities (e.g. AIRTEL, and MTN). In order to enhance information sharing, PACRA must develop an effective feedback mechanism so as to get feedback from companies promptly. This may involve an Online or mobile platform that is easy to use and understood by all and most importantly, one that does expose the public to additional costs. An efficient feedback mechanism would allow PACRA to gather accurate information as well as understanding the needs and concerns of the public. This would be a valuable input into the improvement of compliance procedures and systems within the organization.

\section{Contribution and Implications of the Study}

Despite the large body of research currently available on compliance behaviour, to the best of the researchers' knowledge no studies have been conducted on compliance behaviour as it pertains to filing of company returns. Most focus has been on tax compliance. Therefore, there is a continuous need to contribute towards the body of knowledge in smaller steps, with the new focus on a combination of economic and noneconomic factors. The analysis employed in the current study has attempted to explain compliance behaviour of business owners and in the process have provided several possibilities for future research.

The results of this study illustrate that the TPB, which is based on attitudes and behaviour, offers a useful framework for exploring compliance issues. More research applying the TPB is needed to explore factors that are likely to strongly 
influence intentions to comply (or not comply) and compliance (or noncompliance) behaviour. That is to say, further research is needed to ascertain the strength of the relationship of compliance and the factors identified in the study so as to understand which factors strongly influence compliance and which do not. This may provide PACRA with the tools to tailor its compliance services accordingly, and not simply based compliance initiatives on generic the attributes company owners.

The results of this study shows that the use of Economic deterrent models of using enforcement and penalties to curb illegal activities or those who are liable does not explain compliance behaviour or either do they ensure voluntary compliance. In fact, enforcement comes at a huge cost and some empirical reviews suggest that budgets allocated to enforcements in government institutions are huge and that those in enforcement are usually the target of blame when this activity fails. The use of penalties as well does not guarantee voluntary compliance or understanding of compliance behaviour in fact the payment of penalties makes the public to device other ways of circumventing this. Studies have shown that low expected penalties do not always result in high levels of non-compliance; and prescriptions for more enforcement inputs and higher penalties are usually unfeasible or not cost-effective. Further, courts are not willing to meet out sanctions perceived as excessively severe. Rather, courts tend to impose sanctions that fit the crime, as measured by the illegal gains realized or the social harm caused [14].

The result of not understanding compliance behaviour therefore means government institutions will continue increasing budgets on enforcements which are not cost effective, they will continue to allocate huge financial resources on educational clinics, sensitization and awareness programs which will not result in increased voluntary compliance. If this continues governments shall continue to lose potential revenue in compliance fees. The research also showed that compliance fees are an insignificant influence on compliance, this implies that even reducing fees in the hope that people will comply cannot improve compliance, increase fiscal targets or curb illegal activities until compliance behaviour is understood. Therefore, all compliance strategies should be crafted with full understanding of compliance behaviours in context. This perhaps explains why compliance at PACRA remained at $40 \%$ for many years irrespective of removal of penalties, reduction of fees, going Online, setting up of a compliance unit and embarking on an amnesty.

The study further illustrated that it is possible for a company register to have done away with manual printing of certificates, manual signatures invested massively in technology and have e-registrations-payments system, e-searches-filing, e-signatures and systems Mobile applications but still have low compliance levels. Therefore results showed that an analysis of data analytics elucidates certain variables which are crucial influencers of compliance. The understanding of these variables as already pointed out is crucial. As pointed out at the Corporate 
registers Forum, 2017, Registrar of Companies of Hong Kong Ms Ada Chung noted that technology was necessary but not everything as there were failed cases but of most important is an understanding of a holistic picture. This research therefore reviews an aspect of data analytics that is crucial for compliance levels. These findings were also consistent with the findings in the literature review.

The results of this study illustrate that the TPB, which is based on attitudes and behaviour, offers a useful framework for exploring compliance issues. More research applying the TPB is needed to explore factors that are likely to strongly influence intentions to comply (or not comply) and compliance (or noncompliance) behaviour. That is to say, further research is needed to ascertain the strength of the relationship of compliance and the factors identified in the study so as to understand which factors strongly influence compliance and which do not. This may provide PACRA with the tools to tailor its compliance services accordingly, and not simply base compliance initiatives on generic attributes of company owners.

\section{Acknowledgements}

My gratitude goes to Eliya Lungu and everyone that supported me throughout this research. Last but not the least my thanks go to all the respondents that took part in the research, the entire management of the Graduate School of Business at the University of Zambia and PACRA Management for the information provided, the Registrar \& CEO, and Mr Anthony Bwembya and Assistant Registrar-Commercial Department, Mr Mapani Christopher.

\section{Conflicts of Interest}

The authors declare no conflicts of interest regarding the publication of this paper.

\section{References}

[1] PACRA (2017) PACRA Annual Report 2017. https://www.pacra.org.zm

[2] Salcedo Vargas, M.F., Bell, R., Giannella, V. and Myers, C. (2017) The International Business Registers Report. https://www.ecrforum.org

[3] World Bank (2015) Doing Business Report 2016. https://www.worldbank.org/en/events/2015/11/11/doing-business-2016-report

[4] Wille, J., Belayachi, K.O., de Magalhaes, N. and Meunier, F. (2011) Leveraging Technology to Support Business Registration Reform Insights from Recent Country Experience. Investment Climate in Practice.

[5] PACRA (2018) PACRA Annual Reports. https://www.pacra.org.zm

[6] Sutinen, G. and Kuperan, K. (1999) A Socio-Economical Theory of Regulatory Compliance. International Journal of Social Economics, 26, 174-193. https://doi.org/10.1108/03068299910229569

[7] Ketphat, M. (2013) Application of the Theory of Planned Behavior to Predict Young Drivers' Speeding Behavior. Journal of East Asia Society for Transportation Studies, 10, 2031-2048. 
[8] Martha S. (2012) Applying the Theory of Planned Behaviour and Structural Equation Modelling to Tax Compliance Behaviour: A New Zealand Study. Ph.D. Thesis, University of Canterbury, New Zealand.

[9] Garry, P., Conor, M., Christopher, M. and Emma, H. (2012) Prediction of SelfMonitoring Compliance: Application of the Theory of Planned Behaviour to Chronic Illness Sufferers. https://esource.dbs.ie/handle/10788/1694

[10] Ajzen, I. (1991) The Theory of Planned Behaviour. Organizational Behaviour and Human Decision Processes, 50, 179-211. https://doi.org/10.1016/0749-5978(91)90020-T

[11] Ajzen, I. and Fishbein, M. (1975) Belief, Attitude, Intention and Behaviour: Introduction to Theory and Research. Addison-Wesley, Boston, MA.

[12] Ajzen, I. (2002) Perceived Behavioural Control, Self-Efficiency, Locus of Control, and the Theory of Planned Behaviour. Journal of Applied Social Psychology, 32, 665-683. https://doi.org/10.1111/j.1559-1816.2002.tb00236.x

[13] Hasseldine, J. and Hite, P. (2003) Framing, Gender and Tax Compliance. Journal of Economic Psychology, 24, 517-533. https://doi.org/10.1016/S0167-4870(02)00209-X

[14] Allingham, M.G. and Sandmo, A. (1972) Income Tax Evasion: A Theoretical Analysis. Journal of Public Economics, 1, 323-338. 